\title{
A NATUREZA DA TECNOLOGIA E SEU ENSINO
}

Gilmar Evandro Szczepanik ${ }^{1}$

\section{Resumo:}

A investigação filosófica sobre a tecnologia tem ocupado cada vez mais espaço na agenda dos filósofos profissionais das mais diversas tradições. Com o objetivo de expandir a reflexão filosófica sobre o respectivo tema, o presente texto, busca esclarecer os principais elementos associados à natureza da tecnologia, analisando, consequentemente, as implicações que os mesmos exercem na educação tecnológica. Primeiramente, afastamos a concepção reducionista de tecnologia como ciência aplicada e de tecnociência, alegando que há boas razões para sustentar uma emancipação epistêmica fraca da tecnologia em relação à ciência. Em seguida, falaremos sobre as especificidades que envolvem a educação tecnológica associadas principalmente ao processo de design. Por fim, consideramos a possibilidade de desenvolver uma autêntica e efetiva educação tecnológica.

Palavras-chave: Filosofia. Tecnologia. Design. Educação tecnológica. Ensino.

\section{THE NATURE OF TECHNOLOGY AND IS TEACHING}

\begin{abstract}
:
Philosophical research on technology has increasingly occupied the agenda of professional philosophers from the most diverse traditions. In order to expand the philosophical reflection on the respective theme, this text seeks to clarify the main elements associated with the nature of technology, analysing, consequently, the implications that they have on technological education. First, we tried to move away from the reductionist conception of technology as applied science and technoscience, claiming that there are good reasons to support a weak epistemic emancipation of technology in relation to science. Next, we will talk about the specificities that involve technological education associated mainly with the design process. Finally, we consider the possibility of developing an authentic and effective technological education.
\end{abstract}

Keywords: Philosophy, technology, design, technological education, teaching.

\section{Introdução}

A tecnologia pode se manifestar de diferentes formas, nos lembra Carl Mitcham (1994). A forma mais comum de compreendermos a tecnologia, prossegue o autor, é através dos objetos, mas ela também pode ser concebida como um tipo específico de conhecimento, uma atividade e uma volição. Para Vries (2015), a ideia de que a tecnologia também compreende conhecimento é fundamental, pois isso possibilita que o mesmo pode ser estudado e ensinado, embora ainda seja um assunto menos óbvio e ainda pouco debatido pelos estudiosos da área. Por esse motivo, no transcorrer do texto, daremos ênfase àqueles

\footnotetext{
1 Doutor em Filosofia. Universidade do Centro-Oeste do Paraná - Unicentro. gilmarevandro@unicentro.br.
} 
elementos relacionados à tecnologia como uma forma de conhecimento humano, embora estejamos cientes de que a tecnologia se manifesta como um todo, isto é, ela não se apresenta de forma fragmentada sendo simultaneamente uma atividade, um objeto ou uma volição. Tais elementos encontram-se plena e integralmente incorporados nos objetos, nos dispositivos e nos sistemas técnicos. No entanto, nosso interesse consiste em compreender os pressupostos teóricos, epistemológicos e metodológicos que permeiam e possibilitam a criação, o desenvolvimento e o uso de artefatos e de dispositivos tecnológicos, tendo a preocupação de descrever os elementos de ensino e de pesquisa empregados nas mais diversas áreas.

\section{Sobre a natureza da tecnologia}

Tratar da natureza de algo pressupõe lidar com elementos ou características que definem ou identificam esse ser ou objeto. Assim, falar sobre a natureza da tecnologia implica em dizer o que ela é, apontando as características que lhe são peculiares e/ou aquelas que não a pertencem. Logo, começamos a tratar da natureza da tecnologia, problematizando sua relação e seus vínculos com a ciência ${ }^{2}$.

Primeiramente, pode-se dizer que a tecnologia não pode ser adequadamente compreendida como sendo apenas ciência aplicada. É inegável que, em algumas circunstâncias, a tecnologia se manifesta como o resultado da atividade científica, mas reduzir a tecnologia à ciência aplicada é um exagero. Tal reducionismo é problemático, porque historiadores da tecnologia como Petroski (1994) e Inkster (2009) nos ofereceram numerosos exemplos de artefatos tecnológicos que foram desenvolvidos sem a fundamentação de um conhecimento científico. O exemplo mais emblemático envolve a construção da máquina a vapor. Além dos historiadores, o estudioso ${ }^{3}$ Feibleman (1983) problematiza a noção de ciência aplicada destacando os seguintes elementos: i) o aspecto temporal, pois muitas teorias científicas não são diretamente aplicadas. Algumas teorias levam décadas, outras séculos para possuir alguma aplicabilidade. Outras sequer chegam a ser empregadas. Isso ocorre devido à natureza das teorias científicas que são criadas basicamente com intuito de explicar, ordenar e predizer fatos e fenômenos naturais. Outro aspecto importante é ii) o elemento abstrato das teorias científicas que, para serem postas em prática, necessitam de teorias intermediárias, isto

\footnotetext{
Para saber mais sobre as relações entre a tecnologia e a ciência ver Szczepanik (2015).

Autores como Skolimoski (1983) e Jarvie (1983) também criticam a concepção de tecnologia como ciência aplicada.
}

\begin{tabular}{|l|l|l|l|l|}
\hline Ronita Oialectus & Ano 9 & n. 17 & Maio - Agosto 2020 & p.213-228 \\
\hline
\end{tabular}


é, precisam ser adaptadas e/ou convertidas em procedimentos alternativos capazes de estabelecer uma mediação entre os termos teóricos idealizados e a prática ordinária dos laboratórios. Desse modo, a descoberta, por exemplo, das ondas gravitacionais e dos buracos negros simbolizam um grande avanço para a ciência, mas, não podemos extrair delas imediatamente nenhum dispositivo tecnológico. Por fim, Feibleman pressupõe que iii) a ciência e a tecnologia têm pontos de partida distintos, isto é, a ciência aplicada parte de pressupostos teóricos e busca uma possível aplicabilidade enquanto a tecnologia parece fazer o caminho contrário, ou seja, a partir da identificação de problemas práticos ela busca uma solução, sendo que, muitas vezes, as respostas para tais problemas, ainda não foram antecipadas por nenhuma teoria científica.

Outro argumento frequentemente utilizado para criticar a concepção de tecnologia como ciência aplicada parte do princípio de que a atividade científica contemporânea é dependente de uma infraestrutura tecnológica, isto é, a tecnologia seria "condição de possibilidade para o conhecimento científico" (QUERALTÓ, 1998, p. 95). Neste caso, podese dizer que a tecnologia precede a própria ciência, fornecendo as ferramentas e os mecanismos necessários fundamentais para muitas descobertas científicas. Pode-se dizer que sem esses recursos, a atividade científica estaria comprometida e os cientistas não teriam condições de chegar a resultados muito expressivos. Para que um cientista conduza suas pesquisas de um modo satisfatório, ele geralmente precisa do auxílio de um laboratório e este deve estar equipado com os instrumentos adequados. Em geral, observa Pitt (2010), a ciência moderna conta com uma vasta e variada estrutura tecnológica para realizar suas investigações. Para corroborar esse argumento, podemos lembrar a decisiva sustentação que alguns instrumentos como os aceleradores de partículas, os telescópios atômicos, os microscópios eletrônicos de varredura e os satélites fornecem aos vários ramos científicos. Já é um lugar comum dizer que o telescópio e o microscópio produziram uma verdadeira revolução na física e na biologia, ampliando significativamente o alcance da visão, gerando novas descobertas e possibilitando o desenvolvimento de novas áreas de pesquisa. Assim apresentada, a tecnologia antecede a própria ciência.

A segunda forma de compreendermos a relação ciência e tecnologia é aquela que considera que não é possível concebê-las independentemente, pois encontram-se fundidas, surgindo aquilo que conhecemos como tecnociência. Originariamente, "tecnociência" designava essa imbricação cada vez maior da ciência com a tecnologia, que se tornava uma

\begin{tabular}{|l|l|l|l|l|}
\hline Govista Dialectus & Ano 9 & n. 17 & Maio - Agosto 2020 & p.213-228 \\
\hline
\end{tabular}


"mediação" indispensável da pesquisa, além de fornecer novos objetos de investigação (como as partículas subatômicas). Posteriormente, "tecnociência" passou a designar a inserção cada vez maior da pesquisa científica em projetos industriais, bélicos e políticos, que faz com que a ciência se torne cada vez mais um instrumento, perdendo valor de um fim em si mesma (ver Echeverría 2003). Assim, ciência e tecnologia não são compreendidas como dois ramos que trabalham de uma forma isolada, mas como campos que desenvolvem projetos conjuntamente. Essa espécie de simbiose entre a ciência e a tecnologia ocasionou profundas mudanças nos traços da ciência, alterando significativamente o modo de trabalho dos profissionais envolvidos nos projetos e interferindo diretamente nas demonstrações, nos experimentos, nos objetos de estudo, no processamento de dados e na própria linguagem científica. A tecnociência é, segundo Echeverría (2003), sucessora da macrociência (Big Science) iniciada durante a Segunda Guerra Mundial com megaprojetos como o "Manhattan", produtor da bomba atômica. No imediato pós-guerra, os Estados Unidos primeiro, e outras potências depois, criaram planos de incentivo à ciência e à tecnologia com a finalidade de aumentar a produtividade industrial, melhorar a saúde e a educação da população e desenvolver a capacidade bélica.

Da mesma forma como a tecnologia pode se manifestar, em certas ocasiões, como ciência aplicada ela também pode despontar como tecnociência em alguns cenários, principalmente naqueles que demandam a criação e o desenvolvimento de artefatos e de dispositivos de grandes proporções. No entanto, consideramos essa interpretação muito radical, pois acreditamos que a ciência e a tecnologia podem trabalhar conjuntamente - e de fato o fazem em alguns momentos -, mas nem por isso perdem definitivamente a sua identidade. A existência de empreendimentos tecnocientíficos não deve implicar, por exemplo, no desaparecimento da ciência básica que busca, constantemente, explicar e ordenar o mundo que nos cerca. Ao que nos parece, nem tudo é tecnociência. Ainda bem!

A terceira forma de compreendermos a relação da tecnologia com a ciência é pressupondo que ambas possuem bases epistemológicas distintasque impedem o reducionismo proposto pelas abordagens anteriores e, ao mesmo tempo, permitem identificar suas especificidades e suas peculiaridades. Embora ciência e tecnologia estabeleçam vínculos entre si, ainda assim, elas possuem um conjunto de características que lhes são próprias. A primeira propriedade a ser salientada consiste em dizer que ambas lidam com problemas

\begin{tabular}{|l|l|l|l|l|}
\hline Govista Dialectus & Ano 9 & n. 17 & Maio - Agosto 2020 & p.213-228 \\
\hline
\end{tabular}


específicos, isto é, pode-se dizer que a ciência persegue a resolução de problemas teóricos enquanto a tecnologia se concentra na busca por respostas a problemas pragmáticos.

Assim, pressupondo que ciência e tecnologia buscam solucionar problemas específicos, pode-se presumir também que o percurso metodológico adotado por cada uma delas também é particular. Desse modo, a segunda característica a ser observada consiste em considerar que os métodos utilizados para a resolução dos problemas tecnológicos são distintos daqueles métodos e/ou procedimentos adotados nas áreas científicas. As especificidades metodológicas de ambas as áreas se tornam evidentes, pois se desafiássemos os tecnólogos a solucionar os problemas de suas áreas com os métodos científicos eles provavelmente não teriam êxito, assim como os cientistas possivelmente não obteriam grandes avanços empregando os métodos da tecnologia. Nas áreas científicas, habilidades teóricas relacionadas à abstração, à elaboração de experimentos mentais e à criação de hipótese são requisitos elementares e muito valorizados. Por outro lado, embora essas habilidades sejam também importantes nas áreas tecnológicas, são necessárias outras capacidades como a de produzir desenhos técnicos, de manejar ou desenvolver cuidadosamente uma peça, de ter a criatividade de projetar um dispositivo inovador ou revolucionário. Não é exagero afirmar que ambos os profissionais são submetidos a exigências distintas.

Assim, partindo do princípio de que a ciência e a tecnologia têm objetivos diferentes e lidam com problemas específicos, torna-se possível pensar e sustentar um modelo de racionalidade distinto, pois as estratégias utilizadas para alcançar os objetivos teóricos da ciência são diferentes daquelas empregadas para satisfazer os problemas pragmáticos das áreas tecnológicas. Aqui estaria outro elemento peculiar da tecnologia. Também, a concepção de racionalidade tecnológica parece ser mais ampla, pois as justificativas para a criação, o desenvolvimento e o uso de um artefato tecnológico precisam observar tanto fatores internos relacionados aos princípios técnicos quanto elementos externos implementados pela economia, pelas questões estéticas e pelas preocupações sociais e ambientais. Em outras palavras, nas áreas tecnológicas o número de elementos envolvidos parece ser bem maior que os identificados na ciência, tornando, por esse motivo, a questão mais complexa e de difícil resolução. Assim, faz-se necessário identificar e compreender os diferentes interesses que estão em jogo, procurando acomodá-los e/oucontorná-los de um modo satisfatório. Por fim,

\begin{tabular}{|l|l|l|l|l|}
\hline Q Rovista Dialectus & Ano 9 & n. 17 & Maio - Agosto 2020 & p.213-228 \\
\hline
\end{tabular}


como Queraltó (2003) considerou, a racionalidade tecnológica emerge para solucionar outros tipos de problemas que ultrapassam o campo de atuação da racionalidade científica.

Deste modo, o que percebemos é que não há uma competição entre os dois modelos de racionalidade, ou seja, não se trata de uma exclusão, mas de uma complementação, pois a racionalidade científica serve para justificar adequadamente a ciência, mas, em contrapartida, é insuficiente para legitimar a atividade tecnológica. Resumidamente, podemos dizer: se "racionalidade" significa a maneira de justificar, mediante argumentos, o alcance de resultados, ciência e tecnologia o fazem apelando a critérios parcialmente diferentes, embora compartilhando procedimentos (essencialmente, a discussão dialética).

Por fim, cabe dizer que o progresso tecnológico também é marcado por algumas peculiaridades que permitem diferenciá-lo do progresso científico. Primeiramente, pode-se dizer que o progresso buscado pela ciência e pela tecnologia tem um propósito muito distinto, sendo que o primeiro se encontra voltado basicamente aos fins teóricos, cognitivos e intelectuais enquanto o segundo persegue prioritariamente resultados práticos e pragmáticos, desenvolvendo objetos e procedimentos que tenham a capacidade de realizar funções específicas. Por esse motivo, os critérios que são utilizados para avaliar e verificar o progresso científico são distintos daqueles utilizados para avaliar o progresso tecnológico. Deste modo, os indicadores do progresso científico tendem a levar em consideração somente elementos de natureza teórica, ao passo que tais critérios são insuficientes para descrever e avaliar o progresso tecnológico. Nesse sentido, a noção de progresso tecnológico apresenta-se como mais complexa do que aquela existente na ciência, pois diferentes elementos precisam ser levados em consideração quando decidimos identificar a sua manifestação. Enquanto a ciência (pura) progride levando em consideração apenas critérios epistêmicos como a verdade, a adequação empírica, ou o poder preditivo, a tecnologia não pode ficar restrita aos critérios estritamente técnicos. A maior eficiência é geralmente utilizada como um indicador do progresso tecnológico, mas como vimos, ela deve ser especificada e combinada ou confrontada com outros critérios e valores: sociais, econômicos, políticos, estéticos, ambientais e legais.

Em síntese, ao tratar da natureza da tecnologia necessariamente somos forçados a identificar um conjunto de elementos essenciais a sua identidade. Deste modo, é importante dizer que compreendemos a tecnologia como uma atividade epistêmico-instrumental. Ela

\begin{tabular}{|c|c|c|c|c|}
\hline Ronita Dialectus & Ano 9 & n. 17 & Maio - Agosto 2020 & p.213-228 \\
\hline
\end{tabular}


compreende uma atividade epistêmica porque além de incorporar, utilizar, absorver e reconfigurar uma parte das descobertas, das leis e das teorias científicas, a tecnologia utiliza critérios independentes para avaliar, legitimar e justificar os conhecimentos necessários para suas próprias áreas. Além disso, a tecnologia tem capacidade de produzir um conhecimento genuíno que não pode ser imediatamente derivado e extraído das teorias científicas. Ela é uma atividade instrumental, pois se encontra diretamente relacionada às atividades pragmáticas, visando suprir os desejos e as necessidades do homem. Dito isso, na próxima seção, verificaremos quais são as possíveis implicações relacionadas ao ensino tecnológico geradas pela adoção de cada uma dessas imagens da tecnologia.

\section{As implicações relacionadas ao ensino tecnológico}

Cabe ressaltar, novamente, que a questão da educação tecnológica é um tema ainda pouquíssimo estudado, embora autores como Willians (2015) e Maclen e Wilson (2009) tenham identificado algumas investidas ao longo da história ${ }^{4}$. Maclean e Wilson (2009, p. lxxxviii) consideram, por exemplo, que "o estudo da educação profissional tem uma história de longa data, começando em 1880, quando a urbanização, a mecanização e a industrialização se tornaram as principais forças que impulsionam as sociedades". Willians (2015, p. 202-203), por sua vez, vai ainda mais longe e considera que, "provavelmente isso poderia ser muito mais remontado, talvez às ideias de Comenius e Locke nos anos 1600, e depois de Pestalozzi e Froebel no início dos anos 1800, que desenvolveram posições teóricas sobre aspectos do que hoje chamamos de Educação Tecnológica”.

Contudo, parece consensual que a abordagem predominante do ensino ${ }^{5}$ de tecnologia pressupõe a aplicação da ciência. A noção de tecnologia como ciência aplicada perpassa tanto a mente dos educadores quanto a dos aprendizes, pois ambos cultivam um pano de fundo de que é possível fazer coisas formidáveis e inimagináveis com a ciência. Como já observado nas páginas anteriores, essa abordagem não está totalmente equivocada, pois há algumas ocasiões nas quais é possível aplicar a ciência para desenvolver artefatos e dispositivos tecnológicos. No entanto, tal abordagem não é satisfatória por diferentes razões.

4 Simondon (2007, p. 35) também já havia chamado nossa atenção sobre essa temática ao dizer que "a iniciação às técnicas deve ser colocada sobre o mesmo plano que a educação científica; ela é tão desinteressada quanto a prática das artes, e domina tanto as aplicações práticas quanto a física teórica; ela pode atingir o mesmo grau de abstração e de simbolismo. Uma criança deveria saber o que é uma autorregulação ou uma reação positiva como ela conhece os teoremas matemáticos".

5 Não trataremos da diferenciação entre ensino médio e ensino superior.

\begin{tabular}{|l|l|l|l|l|}
\hline Qovista Dialectus & Ano 9 & n. 17 & Maio - Agosto 2020 & p.213-228 \\
\hline
\end{tabular}


Primeiramente, falar de educação tecnológica a partir da aplicação da ciência pressupõe atribuir maior importância epistemológica à ciência do que à tecnologia, pois, teoricamente, sem a primeira não existiria a segunda. Entretanto, tal pressuposto é muito ambicioso e desproporcional, pois não há uma relação direta entre uma descoberta científica e a criação de um determinado artefato ou dispositivo tecnológico. A história da ciência nos mostra que foram poucos os proponentes de teorias científicas que criaram artefatos e dispositivos tecnológicos funcionais ou revolucionários. Do mesmo modo, não é evidente qual foi a teoria científica empregada ou que serviu de guia para os grandes inventores e construtores de artefatos e dispositivos. Assim, é possível identificar que há uma enorme dificuldade de transferir e implementar o conhecimento científico para áreas ou setores tecnológicos. Um claro e recente exemplo disso pode ser extraído a partir da pandemia ocasionada pelo Covid-19. Aqui, os cientistas conseguiram descobertas importantíssimas, pois identificaram com rigor e precisão - inclusive com o sequenciamento genético - a natureza do vírus, sua capacidade de mutação e sua forma de propagação. Tais descobertas são importantíssimas, pois descrevem causalmenteo aumento do número de doentes e apontam com precisão a causa das mortes, possibilitando realizar previsões precisas sobre a forma de contágio e de disseminação da doença. Entretanto, a posse e o domínio do conhecimento teórico sobre o assunto não é automaticamente convertido em um conhecimento técnico, instrumental e funcional, pois ainda não foi desenvolvido nenhuma droga capaz de promover a cura, demonstrando, mais uma vez, que há um grande hiato entre o conhecimento científico e os artefatos técnicos. Na realidade, é possível identificar uma grande lacuna entre as teorias científicas e os artefatos tecnológicos, pois parece haver muito mais elementos envolvidos no desenvolvimento de artefatos e dispositivos do que aqueles ofertados e disponibilizados pela própria ciência.

Em segundo lugar, a educação tecnológica que presume a aplicação do conhecimento científico tende a enfatizar nos aprendizes a capacidade de tradução e adaptação as teorias científicas. Assim, busca-se exprimir aquilo que está contido nos termos teóricos da ciência em princípios operacionais da tecnologia, deixando de lado uma autêntica investigação tecnológica. Em outras palavras, essa posição subentende que as respostas aos problemas tecnológicos devem ser primeiramente buscadas nas teorias científicas. Se elas ainda não foram encontradas, pressupõem-se que é preciso prosseguir com as investigações científicas para, em um segundo momento, vislumbrar alguma aplicabilidade das descobertas.

\begin{tabular}{|l|l|l|l|l|}
\hline Q Rovista Dialectus & Ano 9 & n. 17 & Maio - Agosto 2020 & p.213-228 \\
\hline
\end{tabular}


Contudo, na próxima seção, demonstraremos a existência de uma genuína pesquisa tecnológica que não ignora as contribuições fornecidas pela própria ciência, mas que transcende o modus operandi científico.

Em terceiro lugar, a educação tecnológica pautada na aplicação do conhecimento científico parece ser ineficaz na resolução de problemas pragmáticos complexos que demandam a utilização de saberes oriundos de diversos ramos teóricos. Geralmente, problemas dessa natureza exigem a criação e o desenvolvimento de artefatos e de dispositivos que jamais foram imaginados e incorporam conhecimentos de áreas remotas como da física, da química, da biologia, da neurociência, da robótica, da mecatrônica que, por sua vez, precisam ser combinados para que possam estabelecer uma sintonia funcional. Não fica claro, por exemplo, como e quais ciências particulares podem contribuir para o desenvolvimento de um artefato tecnológico, pois, quando tomadas aleatoriamente estão mais propícias a formarem um Frankenstein do que estabelecerem uma combinação harmoniosa e funcional.

Por fim, uma educação tecnológica inspirada na mera aplicação do conhecimento científico tende a levar em consideração apenas um conjunto limitado de valores relacionados à eficácia, à eficiência, à durabilidade, à relação custo/benefício, restringindo, consequentemente, a incorporação de outros valores relacionados, por exemplo, como princípios éticos, morais, ambientais, estéticos e sociais. Os valores relacionados às propriedades dos materiais são tidos como prioritários enquanto que os demais valores tendem a ser concebidos como meramente alegóricos, pois podem agregar algum valor ao artefato. Contudo, é evidente que essa dissociação entre quais valores devem ser incorporados ou exercerem primazia nos projetos tecnológicos é problemática. Assim, em síntese, o modelo de educação tecnológica que pressupõe a aplicação da ciência possui sérias lacunas que impactam diretamente, de diferentes formas, a criação e o desenvolvimento de novas tecnologias. Desse modo, torna-se necessário reconhecer tanto as contribuições quanto as lacunas da relação entre ciência e tecnologia, buscando desenvolver uma abordagem mais adequada.

Por outro lado, o entendimento de tecnologia como tecnociência traz consigo outra perspectiva de educação tecnológica, pois envolve um número maior de agentes envolvidos nos projetos. Neste caso, cientistas e engenheiros trabalham conjuntamente com profissionais que, muitas vezes, não possuem uma formação específica em ciência e/ou tecnologia como pode ser o caso de militares, políticos, juristas, industriais, investidores,

\begin{tabular}{|l|l|l|l|l|}
\hline Govista Dialectus & Ano 9 & n. 17 & Maio - Agosto 2020 & p.213-228 \\
\hline
\end{tabular}


gestores e profissionais do marketing. Assim, observada a pluralidade dos membros que compõem uma comunidade tecnocientífica, a educação tecnológica precisa desenvolver habilidades específicas nos aprendizes, entre as quais destacam-se: i) a capacidade de trabalhar em grupo cujos membros possuem formação distinta; ii) a habilidade de solucionar problemas pragmáticos de grande envergadura; iii) aptidão para sintetizar e encontrar um denominador comum diante da pluralidade de posições apresentadas pelos diferentes profissionais; iv) perícia e destreza para identificar e prever os possíveis impactos sociais e ambientais dos projetos tecnocientíficos; v) lidar com a demanda e as exigências dos financiadores do projeto; vi) dimensionar o tempo e os recursos técnicos disponíveis para tal atividade, etc...

Assim, uma das principais especificidades da educação tecnocientífica é estar direcionada à resolução de problemas pragmáticos relacionados, por exemplo, a uma maneira de sintetizar um remédio, de aperfeiçoar determinada produção industrial, de aprimorar uma arma ou um sistema de defesa, de desenvolver um sistema de comunicação mais eficaz ou até criar sistemas e/ou plataformas de ensino mais eficientes. Em outras palavras, ela visa o desenvolvimento de um artefato ou dispositivo útil capaz de solucionar um problema ou um conjunto de problemas específico. Neste caso, um dos pré-requisitos exigidos para os praticantes da tecnociência é a capacidade de inovação. Deve-se aperfeiçoar o que já existe ou criar algo novo mais eficiente. Atualmente, os principais projetos tecnocientíficos se concentram em grandes laboratórios privados associados ao agronegócio (desenvolvendo sementes, insumos e defensivos agrícolas capazes de aumentar a produção de alimentos e de comodities), a indústria farmacêutica (promovendo novas drogas para antigas e novas doenças), ao ramo de transportes (criando protótipos autônomos ou com fontes de energia alternativas) e ao ramo de segurança (concebendo estratégias de ataque e de defesa).

Entretanto, as discussões sobre uma proposta de educação tecnocientífica são praticamente inéditas na literatura que trata dessas questões. Especulamos aqui que isso se deve a uma concepção equivocada da atividade tecnológica, na qual presume-se que a formação e a educação tecnológica antecedem à prática, supondo que os tecnólogos primeiramente precisam estar de posse do conhecimento e dos instrumentos específicos para, em seguida, buscarem respostas e desenvolverem os dispositivos. Na realidade, trataremos de demonstrar na próxima seção que isso não é o caso, pois, ao nosso ver, há uma genuína investigação que precisa ser realizada a cada novo projeto. Outro elemento que parece limitar

\begin{tabular}{|l|l|l|l|l|}
\hline Q Rovista Dialectus & Ano 9 & n. 17 & Maio - Agosto 2020 & p.213-228 \\
\hline
\end{tabular}


o florescimento das investigações sobre a educação tecnocientífica é a natureza dos problemas encarados pela tecnociência, pois os mesmos geralmente demandam largos financiamentos, deixando transparecer que tais projetos são para poucos pesquisadores, produzindo a sensação de que é praticamente impossível fazer parte de uma equipe que se dedica a tais projetos.

Em síntese, como temos visto, a tecnologia pode se manifestar como tecnociência, embora os estudos a respeito de uma educação tecnocientífica ainda se encontrem em estágio embrionário. Assim, torna-se necessário reconhecer as contribuições e os hiatos produzidos também por essa abordagem. Na próxima seção, apresentaremos uma visão que consideramos mais apropriada para a educação tecnológica.

\section{Uma autêntica e efetiva educação tecnológica}

Considera-se uma autêntica e efetiva educação tecnológica aquela educação que é capaz de, além de incorporar as virtudes dos modelos apresentados nas seções anteriores, lidar com problemas pragmáticos que afetam o homem contemporâneo. Trata-se de uma educação autêntica, pois tem o propósito de desenvolver habilidades para solucionar problemas tecnológicos, sejam eles simples ou complexos, oriundos dos diferentes setores da sociedade. A autenticidade é um pré-requisito, pois, em inúmeras situações, faz-se necessário desenvolver um conhecimento que ainda não está disponível em nenhum manual de iniciação científica/tecnológica, pois os problemas enfrentados são completamente inéditos e as respostas precisam ser buscadas do zero. Ela não se resume simplesmente ao ensino de conteúdos ou saberes já conhecidos, pois também deve instruir e preparar os interessados para novas investigações. Não é exagero afirmar que os problemas tecnológicos, em sua grande maioria, são inéditos e desafiam a criatividade e a engenhosidade dos pesquisadores na busca de respostas. Nesse sentido, uma autêntica educação tecnológica deve voltar o olhar para o futuro. Muito mais do que transmitir os conhecimentos existentes, faz-se necessário preparar os interessados para lidar com problemas e acontecimentos futuros, pois a tecnologia tem a possibilidade de projetar o amanhã. Sendo assim, cada novo problema tecnológico a ser solucionado demanda novas investigações e compete à educação tecnológica fomentar uma atitude adequada nos envolvidos para que busquem as respostas mais adequadas possíveis a tais problemas.

Além disso, trata-se de uma educação efetiva, pois tem como finalidade solucionar problemas pragmáticos reais que afetam indivíduos, grupos de pessoas, empresas,

\begin{tabular}{|l|l|l|l|l|}
\hline Q & Movista & Maio - Agosto 2020 & p.213-228 \\
\hline
\end{tabular}


consumidores, meio ambiente, corporações ou o próprio governo. Uma autêntica e efetiva educação tecnológica não tem como objetivo simplesmente humanizar a máquina e também não pode ficar restrita apenas à criação ou ao uso de um artefato ou dispositivo. Ela deve dar conta do aspecto funcional e material e, ao mesmo tempo, deve ultrapassá-los, pois há inúmeros outros elementos que são incorporados no processo de formação e de desenvolvimento tecnológico. Assim, o desafio de uma autêntica e efetiva educação tecnológica não consiste apenas de uma investida para conhecer ou aprender a controlar a máquina com intuito de não ser controlado por ela. Trata-se de compreender todo o processo de design ${ }^{6}$, desde a concepção de artefato/dispositivo, do desenvolvimento, do uso e do descarte adequado do mesmo. Desse modo, consideramos que uma autêntica e efetiva educação tecnológica se dá através do processo de design. A seguir, buscaremos esclarecer como é possível promover e fomentar essa educação.

$\mathrm{Na}$ tentativa de caracterizar aquilo que chamamos de uma autêntica e efetiva educação tecnológica recorremos ao relato feito por Michael (2006, p. 56) no qual ele reconstrói as principais estratégias utilizadas por países como Inglaterra, País de Gales e Escócia, para lidar com a educação tecnológica. Através da criação da Associação de Tecnologia e Design $(\mathrm{DATA})^{7}$ realizada por esses países, fica evidente que a educação tecnológica possui objetivos claros que envolvem, por exemplo, i) preparar os jovens para enfrentar um mundo tecnológico em rápida mudança; ii) capacitá-los a pensar e a intervir criativamente para melhorar esse mundo; iii) desenvolver habilidades necessárias para participar com responsabilidade na vida em casa, na escola e na comunidade (cidadania); iv) ajudar os alunos a se tornarem consumidores e usuários discriminadores de produtos; v) ajudar os alunos a se tornarem autônomos e criativos para resolver problemas; vi) encorajar a capacidade de considerar criticamente os usos, efeitos e valores da dimensão do design e da tecnologia (consciência tecnológica ou alfabetização).

Como observado nos objetivos acima, a formação profissional ou para o mercado de trabalho não aparece como prioridade nem é tida como um elemento essencial dessa nova proposta educacional, pois uma educação que incorpore, defenda e estimule tais pressupostos nada mais é do que uma educação passiva e submissa, que tende a ajustar os indivíduos às forças e aos mecanismos tecnológicos existentes, tornando-os, consequentemente, incapazes

6 Para saber mais sobre o processo de design ver Szczepanik (2016).

7 DATA (Design and Technology Association), em inglês.

\begin{tabular}{|l|c|c|c|c|}
\hline Rovista Dialectus & Ano 9 & n. 17 & Maio - Agosto 2020 & p.213-228 \\
\hline
\end{tabular}


de pensar ou propor transformações tecnológicas significativas. Por estarmos inseridos em um mundo que se encontra mediado tecnologicamente, faz-se necessário, sugere Darkes (2006), desenvolver uma consciência crítica nos jovens para que eles possam entender a maneira como suas vidas são e serão moldadas por ele.

Assim, os propósitos da educação tecnológica apresentados no parágrafo anterior fundamentam uma autêntica e efetiva educação tecnológica, pois desafiam os jovens e demais estudiosos a se posicionarem diante da tecnologia, deixando de ser meros espectadores para se tornarem sujeitos emancipados. No objetivo $i$ ) encontramos um dos elementos característicos da tecnologia que é seu caráter dinâmico e progressivo. Desde a Antiguidade a técnica e a tecnologia atuaram como agentes de transformação, mas é inegável que tais mudanças foram amplamente aceleradas pelos avanços sistemáticos das novas tecnologias. Desse modo, uma autêntica educação tecnológica deve ser capaz de preparar os indivíduos a viver em tal mundo como sujeitos e atores, no qual eles sejam consumidores, mas também proponentes de novas tecnologias. Em outras palavras, tal educação deve capacitar para que os indivíduos saibam lidar com todo esse universo tecnológico, mas também que se sintam capazes de pensar e intervir criticamente nesse mundo, como reza o objetivo $i i)$. Isso se deve porque a inovação é um dos elementos característicos da nova tecnologia. Em outras palavras, a educação tecnológica não deve apenas formar bons e sábios expectadores ou críticos do modelo tecnológico, mas deve fornecer competências e habilidades para que possam intervir de modo responsável, como pressupõe os objetivos iii, $i v, v$ e vi. Pode-se dizer que essa nova proposta de educação tecnológica não se resume as estratégias de ensino, pois quando falamos em uma intervenção responsável estamos nos referindo às fases investigativas que antecedem a materialização e ao desenvolvimento de um artefato ou de um dispositivo técnico.

A criação e o desenvolvimento de tecnologias mais adequadas e mais responsáveis social e ambientalmente deve ser uma preocupação constante para os novos projetos e empreendimentos tecnológicos. Deste modo, parece-nos que o novo modelo de educação tecnológica precisa incorporar um conjunto de valores que transcendam a mera tecnicidade, pois já não basta que um artefato tecnológico funcione de modo eficaz e eficiente. Assim, os objetivos apresentados pela DATA parecem ser uma convocação ao engajamento responsável no desenvolvimento de novas tecnologias.

Os pressupostos filosóficos incorporados em tais objetivos são muito fecundos para a nossa reflexão sobre uma autêntica e efetiva educação tecnológica, pois permitem

\begin{tabular}{|l|l|l|l|l|}
\hline Q Rovista Dialectus & Ano 9 & n. 17 & Maio - Agosto 2020 & p.213-228 \\
\hline
\end{tabular}


enfrentar uma concepção determinista e unilateral amplamente difundida na literatura filosófica sobre a tecnologia. Feenberg (2019, p. 32), por exemplo, é um grande crítico do determinismo tecnológico, pois pressupõe que "o determinismo baseia-se na suposição de que as tecnologias têm uma lógica funcional autônoma, que se pode explicar sem qualquer referência à sociedade", ou seja, a tecnologia traça seu percurso de modo unilateral e fixo, fazendo com que os indivíduos e as instituições sociais se moldem aos imperativos tecnológicos. Entretanto, os objetivos listados acima parecem apontar em uma direção oposta, pois ao invés de fundamentarem um modelo hierárquico e tradicional, parecem sinalizar para um modelo mais democrático e participativo. A democratização da tecnologia proposta por Feenberg, não diz respeito apenas à democratização do acesso aos bens e dispositivos tecnológicos, mas envolve também a ampliação dos atores e dos valores envolvidos no processo de design de novas tecnologias. Tal ampliação, como também a diversificação dos valores levados em consideração na tomada de decisão do processo de design, ajuda a promover o surgimento e o desenvolvimento de tecnologias múltiplas e mais engajadas socialmente. Trata-se de tecnologias robustas, isto é, tecnologias sensíveis ao contexto e aos valores sociais nos quais elas são concebidas.

Entretanto, para que seja possível democratizar a tecnologia e torna-la múltipla e plural, precisamos instruir e capacitar nossos jovens estudantes para que despertem o interesse pela construção de tecnologias engajadas socialmente.

\section{Considerações finais}

No transcorrer do presente texto buscamos apresentar algumas das principais características frequentemente associadas à natureza da tecnologia, explorando as implicações associadas ao ensino da tecnologia decorrentes da adoção de cada uma delas. De um modo geral, identificamos que a tecnologia pode ser parcialmente compreendida como ciência aplicada e também como tecnociência. Embora essas duas abordagens ajudem a esclarecer a identidade da tecnologia, consideramos muito problemático considera-las como adequadas, pois elas são abordagens muito restritivas e produzem, mesmo que involuntariamente, um grande problema na educação científica, pois, apesar de algumas virtudes, produzem lacunas que são facilmente preenchidas. Elas, por exemplo, deixam transparecer que dificilmente alguém pode ser um bom tecnólogo ou um grande tecnicista sem antes ser um razoável cientista ou deter o domínio de alguns ramos científicos. Ao mesmo tempo, ao apresentar a

\begin{tabular}{|c|c|c|c|c|}
\hline Gevista Dialectus & Ano 9 & n. 17 & Maio - Agosto 2020 & p.213-228 \\
\hline
\end{tabular}


tecnologia apenas como tecnociência pode desencorajar mentes talentosas a desenvolverem tecnologias, pois transmite uma imagem equivocada de que a legítima tecnologia somente pode ser criada e produzida em grandes laboratórios e em grandes centros tecnológicos.

Ao nosso ver, a melhor forma de compreendermos a tecnologia é concebê-la como emancipada epistemologicamente da ciência, isto é, buscando-a como uma área de conhecimento designada a tratar um conjunto de problemas pragmáticos específicos. A busca pelas respostas envolve uma genuína investigação tecnológica capaz de criar conhecimentos e desenvolver métodos e técnicas inéditas. Todo esse percurso investigativo é legitimado por um modelo de racionalidade tecnológica capaz de justificar as diferentes estratégias adotadas. Por fim, a concepção do progresso tecnológico para sacramentar a emancipação da tecnologia em relação à ciência, pois invoca um conjunto de indicadores que não podem ser extraídos das áreas científicas. Conceber a tecnologia de tal forma, nos possibilita pensar em instituir uma nova proposta de educação tecnológica, muito mais genuína e eficiente.

Acreditamos que há bons argumentos que fundamentam essa autêntica e efetiva educação tecnológica que deve ter por princípio uma avaliação fidedigna das atuais tecnologias, mas, ao mesmo tempo, capacitar e estimular o desenvolvimento de tecnologias cada vez mais responsáveis e adequadas social e ambientalmente. Tal proposta educativa visa democratizar a tecnologia, capacitando e incluindo cada vez mais novos atores ao longo do processo de design. Isso somente é possível devido ao fato de os problemas tecnológicos suportarem diferentes respostas, isto é, não existe apenas uma única resposta tecnológica. Há várias formas de se solucionar o mesmo problema. Quanto maior for o número e mais diversas forem as respostas apresentadas, maiores serão as chances de desenvolver-se uma tecnologia mais adequada.

\section{Referências}

DAKERS, J. R. (Ed.). Defining technological literacy towards and epistemological framework. New York: Palgrave Macmillan, 2006.

ECHEVERRÍA, Javier. La revolución tecnocientífica. Madrid: Fondo de Cultura Económica de España, 2003.

FEIBLEMAN, J. Pure science, applied science, and technology: An attempt at definitions. In: Philosophy and technology: readings in the philosophical problems of technology. New York: The Free Press, 1983.

INKSTER, Ian. (Ed.). History of technology. New York: Continuum, 2009.

\begin{tabular}{|l|l|l|l|l|}
\hline Qovista Dialectus & Ano 9 & n. 17 & Maio - Agosto 2020 & p.213-228 \\
\hline
\end{tabular}


JARVIE, I.C. Technology and the structure of knowledge. In: MITCHAM, C. MACKEY, R. Philosophy and technology: reading in the philosophical problems of technology. New York: The Free Press, 1983.

MACLEAN, R., \& WILSON, D. Introduction. In R. Maclean\& D. Wilson (Eds.), International handbook of education for the changing world of work (pp. 1xxiii-cxii). Dordrecht: Springer. 2009.

MICHAEL, M. How to understand mundane technology: new way so thinking about humantechnology relations. In: DAKERS, J. R. (Ed.). Defining technological literacy towards and epistemological framework. New York: Palgrave Macmillan, 2006.

MITCHAM, C. Thinking through technology: the path between engineering and philosophy. Chicago: The University of Chicago Press, 1994.

PETROSKI, H. The evolution of use things. New York: Vintage, 1994. PITT, J. Philosophy, engineering, and the sciences. In: POEL, Ibo van de; GOLDBERG, David E (Editors). Philosophy and engineering: an emerging agenda. New York, Springer, 2010.

QUERALTÓ. R. Ética, tecnología y valores en la sociedad global: el caballo de troya al revés. Madrid: Editorial Tecnos, 2003.

. Technology as a new condition of possibility of scientific knowledge. In: Phil \&

Tech 4:2 Winter, 1998.

WILLIAMS, P. J. Vocation and general technology education. In: WILLIAMS, P.J.; JONES, A.; BUNTTING, C. $(E d s)$. The future of technology education. [S/R].

VRIES, Marc J. Translating customer requirements into technical specifications. In: MEIJERS, Anthonie W.M. (Editor). Philosophy of technology and engineering sciences (Handbook of the philosophy of science). Amsterdam, Elsevier, 2009.

SIMONDON, G. El modo de existencia de los objetos técnicos. Buenos Aires: Promoteo Libros, 2007.

SKOLIMOWSKI, H. The structure of thinking in technology. In: MITCHAM, C. MACKEY, R. Philosophy and technology: reading in the philosophical problems of technology. New York: The Free Press, 1983.

SZCZEPANIK, G. 2017. O design como um modelo metodológico para a tecnologia. Pensando - Revista de Filosofia. Teresina. Vol. 8, n.15, 2017.

A relação entre ciência e tecnologia a partir de três modelos teóricos distintos.

Dois pontos: Curitiba, São Carlos. Vol. 12, n. 1, abril de 2015.

\begin{tabular}{|c|c|c|c|c|}
\hline Govista Dialectus & Ano 9 & n. 17 & Maio - Agosto 2020 & p.213-228 \\
\hline
\end{tabular}

